\title{
Strength and fatigue of an ultrafine-grained Al-Cu-Mg alloy
}

\author{
Elvira Khafizova ${ }^{1, *}$, Rinat Islamgaliev $^{1}$, and Vil Sitdikov ${ }^{1}$ \\ ${ }^{1}$ Ufa State Aviation Technical University, 12 K.Marx St., 450008 Ufa, Russia
}

\begin{abstract}
The dependence of strength and fatigue on microstructure of the $\mathrm{Al}-\mathrm{Cu}-\mathrm{Mg}$ alloy has been investigated. Various microstructures of the alloy were produced: the one with a coarse-grained (CG) structure after T6 heat treatment; the one with a homogeneous ultrafine-grained (UFG) structure and the one with a bimodal (mixed) structure, both processed by equal-channel angular pressing (ECAP). The mean grain size and morphology of precipitates were studied by transmission electron microscopy. The ultimate tensile strength and the fatigue endurance limit were determined using the tensile and fatigue tests of standard specimens. It is established that the formation of a homogeneous UFG structure and of a bimodal (mixed) structure alloy contributes to a significant increase in microhardness by $16 \%$ and $60 \%$, and an increase of the ultimate tensile strength by 20 and $52 \%$, respectively, as compared to the samples subjected to T6 heat treatment. Fatigue tests show that the alloy with a bimodal (mixed) structure has the highest fatigue endurance limit, $45 \%$ higher than in the sample subjected to T6 heat treatment. In contrast, the formation of a homogeneous UFG structure enables increasing the fatigue endurance limit by $15 \%$ only.
\end{abstract}

\section{Introduction}

Aluminum alloys of the Al-Cu-Mg system are widely used as structural materials. Today, an important task is to enhance their strength and fatigue in order to expand their application areas in the aircraft industry and increase the service life of parts.

One of the ways to solve this task is the formation of an ultrafine-grained structure by severe plastic deformation (SPD) [1-4].

It is well known that grain refinement in various metals and alloys is accompanied by a significant enhancement in strength and a decrease in ductility [5-8]. Meanwhile, the structural features and mechanical properties of UFG aluminum alloys essentially depend on the regimes of severe plastic deformation and a material's chemical composition, determining the contributions of solidsolution strengthening and precipitation hardening. Besides, UFG materials exhibit enhanced grain-boundary diffusion, which in the conditions of SPD may lead to a decrease in the aging temperature and time, required for the formation of precipitates [8,9-11]. In their turn, the phase composition, volume fraction and size of precipitates may have an essential effect on the strength and fatigue of UFG aluminum alloys. Therefore, defining the UFG structure parameters that lead to the enhancement in the strength and fatigue properties of aluminum alloys is an important task.

As demonstrated by experimental research, an increase in the strength of aluminum alloys through grain refinement does not always lead to an increase in fatigue [12-15]. At present, two approaches are proposed for raising the fatigue of UFG materials. The first method is additional annealing after SPD processing, leading to a reduction in the initial dislocation density and internal microstresses, as well as to the relaxation of nonequilibrium grain boundaries. However, the use of this approach may result in the coarsening of dispersed particles and, consequently, to the softening of UFG aluminum alloys. The second approach ethod is the formation of a bimodal structure, where micron-sized grains are responsible for the ductility, while nano-sized grains are responsible for the strength [16]. The second approads has not been sufficiently studied so far. As a consequence of the above, the structural features determining the fatigue of UFG aluminum alloys are still a subject of study.

In this connection, the aim of the present work is to establish the relationship between the structural features and fatigue of an aluminum alloy of the $\mathrm{Al}-\mathrm{Cu}-\mathrm{Mg}$ system, and to study the effect of cyclic loads on a material's structure, using the $\mathrm{Al}-\mathrm{Cu}-\mathrm{Mg}$ alloy as an example.

\section{Material and Research Methods}

As the materials for the study, the aluminum alloy of the $\mathrm{Al}-\mathrm{Cu}-\mathrm{Mg}$ system was selected (Russion designation AK41). The alloy's chemical composition is presented in table 1 .

Table 1. Chemical composition of the Al-Cu-Mg alloy, wt. \%

\begin{tabular}{|l|l|l|l|l|l|l|l|l|}
\hline $\mathrm{Fe}$ & $\mathrm{Si}$ & $\mathrm{Mn}$ & $\mathrm{Ti}$ & $\mathrm{Al}$ & $\mathrm{Cu}$ & $\mathrm{Ni}$ & $\mathrm{Mg}$ & $\mathrm{Zn}$ \\
\hline 0.98 & 0.05 & 0.04 & 0.02 & 93.8 & 2.33 & 1.04 & 1.65 & 0.02 \\
\hline
\end{tabular}

The alloy was investigated in three states. «State 1» was produced by $\mathrm{T} 6$ heat treatment, where a coarsegrained structure with a mean grain size of $100 \mu \mathrm{m}$ was

\footnotetext{
* Corresponding author: ela.90@mail.ru
} 
formed. Produced using: heating to a temperature of $530^{\circ} \mathrm{C}$, holding at this temperature for one hour, water quenching, aging at a temperature of $190{ }^{\circ} \mathrm{C}$ for 7 hours and air cooling. Using equal-channel angular pressing (ECAP), two other types of structures were produced: «State 2» - a homogeneous UFG structure (ECAP angle $120^{\circ}$, route $\mathrm{Bc}$, diameter $40 \mathrm{~mm}$, number of passes 6 , $160^{\circ} \mathrm{C}$ ) and «State $3 »-$ a bimodal (mixed) structure (ECAP angle $90^{\circ}$, route $\mathrm{Bc}$, diameter $20 \mathrm{~mm}$, number of passes $\left.2,160^{\circ} \mathrm{C}\right)[17,18]$. Their structural models are presented in fig. 1.

In all the states, there are present $\mathrm{Al}_{9} \mathrm{FeNi}$ intermetallic particles which are not shown in the models, since their sizes and volume fractions remain unchanged. Also present are the dispersed particles of two phases, $\mathrm{\Theta}\left(\mathrm{Al}_{2} \mathrm{Cu}\right)$ and $\mathrm{S}$ $\left(\mathrm{Al}_{2} \mathrm{CuMg}\right)$, which promote strengthening and thermal stability in the AK4-1 alloy. In «State 1» the S phase has a rod-like shape, the $\Theta$ phase has a globular shape, and their sizes reach $2 \mu \mathrm{m}$. The structural feature of «State 2 » is that the UFG structure has grains with sizes of $1.5 \mu \mathrm{m}$ and a width of $500 \mathrm{~nm}$ in the longitudinal section and $480 \mathrm{~nm}$ in the transverse section, and there are present dispersed particles of the phases $\Theta^{\prime}, \Theta$ and $S$, having sizes of 20, 60 and $80 \mathrm{~nm}$, respectively. The feature of «State 3 » is a bimodal (mixed) structure, where in the longitudinal and transverse sections a UFG structure is formed, with grain sizes of $250 \mathrm{~nm}$, and bands with a width of 200-300 nm, and there are also present dispersed particles of the phases $\Theta^{\prime}, \Theta$ and $\mathrm{S}$, having sizes of 10,40 and $60 \mathrm{~nm}$, respectively.

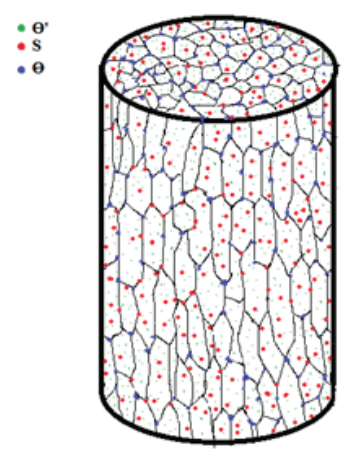

(a)

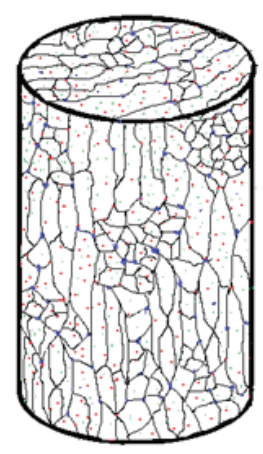

(b)
Fig. 1. Structural models of the samples after different types of treatment: (a) «State 1»; (b) «State 2»;

Microhardness was tested by the Vickers method, using a Buehler «Micromet 5101» device with a pyramidal diamond indenter under a load of $1 \mathrm{~N}$ and with a time under load of 10 seconds.

The strength under tension was tested, using cylidrical specimens with a gauge length of $15 \mathrm{~mm}$ and a diameter of $3 \mathrm{~mm}$. The tests were conducted on an Instron tensiletesting machine at $20^{\circ} \mathrm{C}$ and $175^{\circ} \mathrm{C}$ with a crosshead speed of $1 \mathrm{~mm} / \mathrm{min}\left(\sim 1 \cdot 10^{-3} \mathrm{~s}^{-1}\right)$.

The fatigue tests were performed using two methods. In the first case, the specimens were studied in testing machines - high-frequency pulsators Amsler 100 HFP 5100 and Amsler 300 HFP 5100 (Zwick/Roell) under the axial loading of a specimen at a temperature of $20^{\circ} \mathrm{C}$, the stress ratio was $R_{\sigma}=0.1$ with $10^{7}$ cycles to failure. In the second case, the fatigue tests were conducted as cantilever- bending tests with rotation at a frequency of $50 \mathrm{~Hz}$ using stress ratio $R_{\sigma}=-1$ and $10^{7}$ cycles to failure.

In all the states, the specimens, subjected to high-cycle fatigue testing, were studied in terms of the effect of cyclic loads on the material's structure in the vicinity of the fracture zone (see Fig. 2) by transmission electron microscopy and X-ray diffraction analysis.

Structural studies were performed using transmission electron microscopy on a JEOL - 2100 microscope with an accelerating voltage of $200 \mathrm{kV}$, equipped with an INCAxsight attachment that enables elemental energy-dispersive analysis.

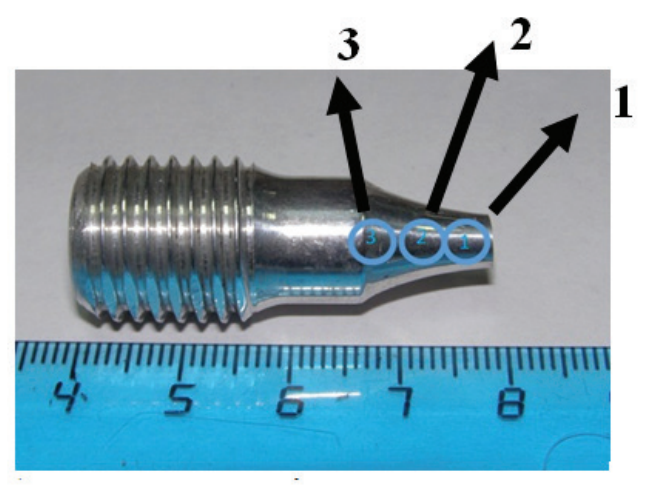

Fig. 2. Specimen of the Al-Cu-Mg alloy after fatigue tests: 1, 2, 3 - the areas under study

X-ray diffraction of the samples was performed using a Rigaku Ultima IV diffractometer in $\mathrm{Cu}-\mathrm{K} \alpha$ radiation with a wave length of $\lambda=1.54418 \AA$.

\section{Results and Discussion}

Formation of «State 2» and «State 3» in the alloy has contributed to a considerable increase in microhardness by $16 \%$ and $60 \%$, respectively, as compared to «State $1 »$. Ultimate tensile strength has grown by 20 and $52 \%$, respectively, and at the same time, elongation to failure has decreased two-fold. Tensile tests of the UFG alloy at a temperature of $175^{\circ} \mathrm{C}$ demonstrate that UTS has decreased only slightly, which confirms the thermal stability of the mechanical properties of the alloy in the UFG state up to a temperature of $175^{\circ} \mathrm{C}$ (Table 2).

The enhanced strength of the UFG samples is the result of a strong grain structure refinement and precipitation hardening, since the reduction in the elongation to failure can be attributed to the presence of internal stresses around the particles and in the vicinity of grain boundaries, impeding the development, generation and movement of dislocations. In the UFG samples, there is also observed a short stade of strain hardening. As it is well known, at the stage of strain hardening there occurs an increase in dislocation density. In the UFG material the distance between grain boundaries is much larger, therefore dislocations reach the opposite grain boundary faster and become annihilated. This can explain the short stage of strain hardening in the UFG samples and, consequently, the small uniform elongation . 
Table 2. Mechanical properties of the $\mathrm{Al}-\mathrm{Cu}-\mathrm{Mg}$ alloy

\begin{tabular}{|c|c|c|c|c|c|}
\hline State & $\mathrm{t},{ }^{\circ} \mathrm{C}$ & $\begin{array}{l}\mathrm{HV}, \\
\mathrm{MPa}\end{array}$ & $\begin{array}{l}\sigma_{\mathrm{B}}, \\
\mathrm{MPa}\end{array}$ & $\begin{array}{l}\sigma_{0.2} \\
\mathrm{MPa}\end{array}$ & $\delta, \%$ \\
\hline \multirow[t]{2}{*}{ «1» } & $20^{\circ} \mathrm{C}$ & $1220 \pm 8$ & $370 \pm 3$ & $320 \pm 5$ & $16 \pm 2$ \\
\hline & $175^{\circ} \mathrm{C}$ & - & $360 \pm 4$ & $306 \pm 5$ & $18 \pm 3$ \\
\hline \multirow[t]{2}{*}{ «2» } & $20^{\circ} \mathrm{C}$ & $1408 \pm 37$ & $460 \pm 8$ & $420 \pm 5$ & $7 \pm 1$ \\
\hline & $175^{\circ} \mathrm{C}$ & - & $430 \pm 5$ & $394 \pm 4$ & $8 \pm 1.5$ \\
\hline \multirow[t]{2}{*}{$\ll 3 »$} & $20^{\circ} \mathrm{C}$ & $1980 \pm 20$ & $566 \pm 10$ & $520 \pm 6$ & $8 \pm 1$ \\
\hline & $175^{\circ} \mathrm{C}$ & ב & $530 \pm 4$ & $495 \pm 5$ & $7 \pm 2$ \\
\hline
\end{tabular}

The large difference between «State $2 »$ and «State $3 »$ can be attributed to the difference in dislocation density, sizes of precipitates and structural elements ((sub)grains) $[17,18]$. Apparently, due to the long exposure at temperature of aging and large strains in «State 2 » there is observed a noticeable increase in the sizes of the second phases, accompanied by a loss of coherence. Due to the strong distortions of the crystal lattice and the activation of diffision processes, the material, exposed to the temperature of aging for a long period of time, loses a part of the strengthening effect of these particles.

Fatigue tests of the «tension-compression» type under an asymmetrical cycle $\mathrm{R}=0.1$ demonstrate that in the alloy the formation of a homogeneous UFG structure («State $2 »)$ has led to an increase in the fatigue endurance limit by $15 \%$ as compared to «State $1 »($ Fig. 3$)$.

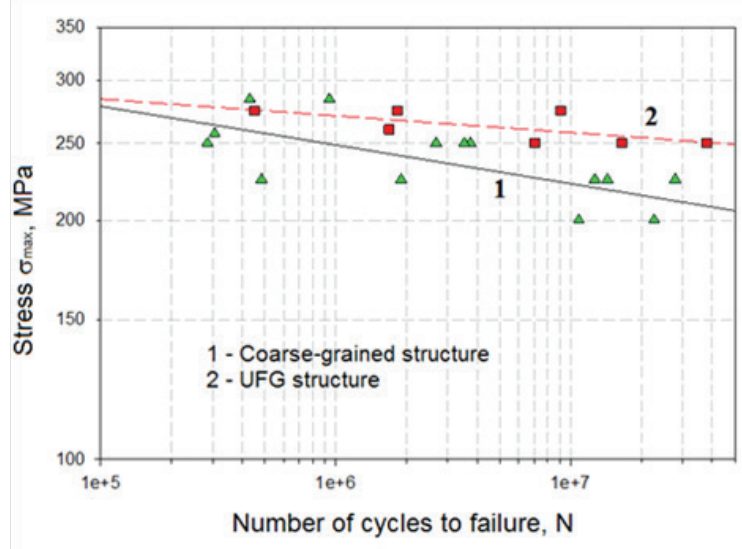

Fig. 3. The stress amplitude as a function of the number of cycles for the $\mathrm{Al}-\mathrm{Cu}-\mathrm{Mg}$ alloy in « State 1» (the lower curve) and « State 2» (the upper curve).

Fig. 4 shows the stress-cycle curves for the alloy in «State 1» and «State 3». Fatigue tests reveal that after ECAP processing the fatigue endurance limit is $250 \mathrm{MPa}$, whereas in the state after T6 it was $170 \mathrm{MPa}$. Thus, it can be concluded that ECAP processing enables increasing the fatigue endurance limit of the alloy approximately by $47 \%$ as compared to the T6 heat treatment.

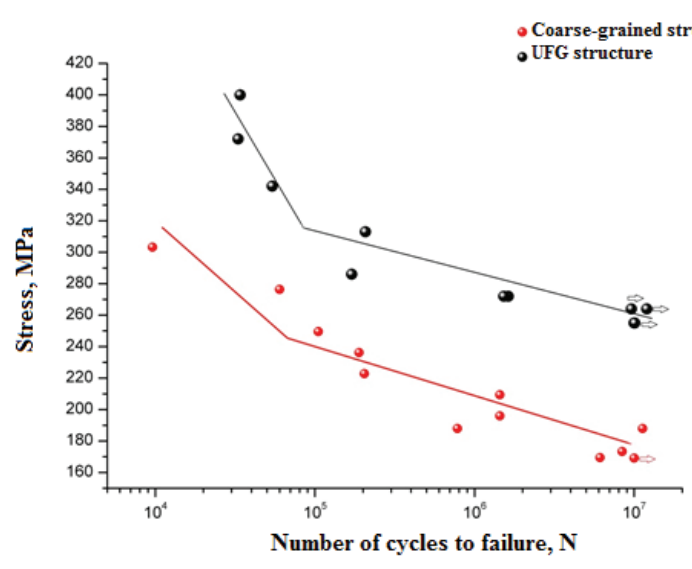

Fig. 4. The stress amplitude as a function of the number of cycles for the Al-Cu-Mg alloy in «State 1» (the lower curve) and «State $3 »$ (the upper curve).

Note should be made that for standard specimens, the resistance to high-cycle fatigue under an asymmetrical cycle $(R=0.1)$, as compared to a symmetrical cycle $(R=-1)$, has a higher value of $\sigma_{\max }$.

Apparently, the increase in fatigue strength in the ECAP-processed samples was achieved due to a strong grain refinement, as well as due to the presence of particles ensuring precipitation hardening.

Study of the effect of cyclic loads on the material's structure in the vicinity of the fracture zone by X-ray diffraction reveals that the closer is a zone to the fracture surface, the more microdistortions of the crystal lattice are observed $\left(<\varepsilon^{2}>^{1 / 2}\right)$, the higher is the dislocation density $(p \perp)$, and, correspondingly, the smaller is the coherent scattering domain size. Also observed is a decrease in the lattice parameter $(a)$, which is related to the precipitation and coarsening of dispersed particles in the fracture region for UFG and CG samples (Table 3), which has also been confirmed by TEM.

Table 3. The results of X-ray diffraction analysis of samples in «State $1 »$ and «State $2 »$

\begin{tabular}{|c|c|c|c|c|}
\hline & Zone & $a, \AA$ & $<\varepsilon^{2}>1 / 2, \%$ & $\begin{array}{c}\perp+ \\
, 10^{14} \mathrm{~m}^{-} \\
2\end{array}$ \\
\hline \multirow{3}{*}{ State1 } & 1 & $4.0546 \pm 0.0001$ & $0.072 \pm 0.002$ & 0.64 \\
\hline & 2 & $4.0561 \pm 0.0001$ & $0.053 \pm 0.004$ & 0.46 \\
\hline & 3 & $4.0584 \pm 0.0001$ & $0.047 \pm 0.001$ & 0.36 \\
\hline \multicolumn{2}{|c|}{ CG before fatigue } & $4.0587 \pm 0.0001$ & $0.045 \pm 0.001$ & 0.32 \\
\hline \multirow{3}{*}{ State2 } & 1 & $4.0538 \pm 0.0001$ & $0.191 \pm 0.003$ & 3.67 \\
\hline & 2 & $4.0540 \pm 0.0001$ & $0.185 \pm 0.002$ & 3.36 \\
\hline & 3 & $4.0541 \pm 0.0001$ & $0.173 \pm 0.002$ & 3.12 \\
\hline \multicolumn{2}{|c|}{ UFG before fatigue } & $4.0542 \pm 0.0001$ & $0.167 \pm 0.002$ & 2.95 \\
\hline
\end{tabular}

In the structure of the UFG samples, subjected to fatigue tests, dispersed particles of three phases have been found. Comparative studies of all the three regions reveal that the particles of the phases $\Theta$ and $\mathrm{S}$, located closer to the fracture surface, have grown in size to $230 \mathrm{~nm}$ (Fig. $5 a)$. In addition, their volume fraction has increased. The closer to the fracture zone, the higher is the dislocation density in the grain interiors. There are observed areas where particles of the $\Theta^{\prime}$ phase have a high density. In the second zone, the volume fraction of the particles and their 
size are smaller in comparison with the first zone (Fig. 5b). In the third zone, there is observed a structure corresponding to a regular structure for this state prior to fatigue testing (Fig. 5c).

In the samples after T6 heat treatment, irrespective of the type of loading, similar changes have also occurred. There is also observed a high dislocation density in the vicinity of the fracture zone, particles of the $\Theta$ phase have appeared at grain boundaries, particles of the $\mathrm{S}$ phase are found in the structure as well.

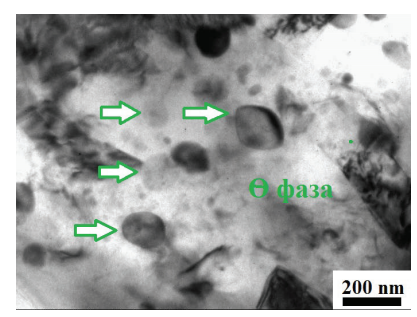

a

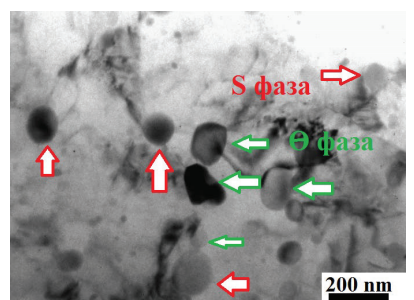

b

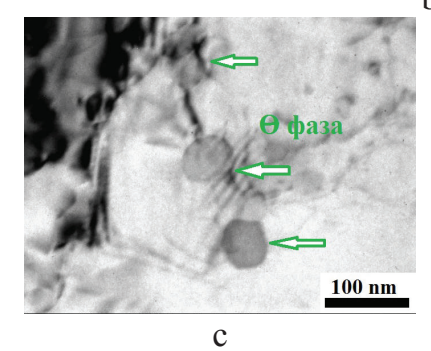

Fig. 5. Typical images of the structure after the fatigue tests for the UFG specimen in "State 2": a - zone 1, b-zone 2, c-zone 3.

On the basis of these data, it is possible to make an assumption that during the fatigue tests there occurs activation of diffusion processes in the sample's fracture zone, and the particles coarsen as a result of dynamic aging.

\section{Conclusions}

Thus, this study has demonstrated that the Al-Cu-Mg alloy with a bimodal (mixed) structure is capable of exhibiting the values of UTS and endurance limit that are 1.5 times higher than the respective values of the sample subjected to the T6 heat treatment, while a homogeneous UFG structure leads to a smaller growth in the material's UTS and fatigue endurance limit.

For this alloy, of great importance is the processing temperature and the time of processing at this temperature, since during the deformation there occurs activation of diffusion processes, which reduces the time of precipitation of dispersed particles playing an important role in the strengthening.

It has been established that during fatigue testing in all the states there is observed activation of diffusion processes, leading to further precipitation and coarsening of particles due to the heating of the sample in the fracture zone.

This work was conducted under RFBR project No. 16-38-00507 performed by young scientists («My first grant»).

\section{References}

1. R. Z. Valiev, R. K. Islamgaliev, I. V. Alexandrov, Progress in Materials Science 45, 103-189 (2000) DOI:10.1016/S0079-6425(99)00007-9

2. R. Z. Valiev, T.G. Langdon, Progress in Materials Science 51, 881-981 (2006) DOI:10.1016/j.pmatsci.2006.02.003

3. A.P. Zhilyaev, T.G. Langdon, Progress in Materials Science 53, 893-979 (2008)

4. R.Z. Valiev, A.P. Zhilyaev, T.G. Langdon, Bulk Nanostructured Materials: Fundamentals and Applications (John Wiley \& Sons Inc., 2014)

5. R. K. Islamgaliev, M. A. Nikitina, A. F. Kamalov, Materials Science Forum, Vols. 667-669, 331-336 (2011)

DOI: 10.4028/www.scientific.net/MSF.667-669.331

6. G. Nurislamova, X. Sauvage, M. Murashkin, R. Islamgaliev, R. Valiev, Phil. Mag. Lett. 88 (6), 459466 (2008) DOI:10.1080/09500830802186938

7. O. Kulyasova, R.K. Islamgaliev, B. Mingler, M. Zehetbauer, Mat. Sci. Eng. A. 503, 176-180 (2009) DOI: org/10.1016/j.msea.2008.03.057

8. E. Bobruk, I Sabirov, V Kazykhanov, R Valiev, M Murashkin, IOP Conf. Series: Materials Science and Engineering 63, 012116 (2014) DOI:10.1088/1757-899X/63/1/012116

9. W. Huang, Z. Liua, M. Lin, X. Zhou, L. Zhao, A. Ning, S. Zeng, Materials Science and Engineering A 546, $26-33$ (2012).DOI:org/10.1016/j.msea.2012.03.010

10. E.V. Bobruk, M.Yu. Murashkin, V.U. Kazykhanov and R.Z. Valiev, Rev. Adv. Mater. Sci 31, $14-34$ (2012)

11. I.G. Brodova, I.G. Shirinkina, A.N. Petrova, O.V. Antonova, V.P. Pilyugin, The Physics of Metals and Metallography 111(6), p. 630-638 (2011) DOI:10.1134/S0031918X11050036

12. Y. Estrin, A. Vinogradov, International Journal of Fatigue 32, 898-907 (2010)

DOI:org/10.1016/j.ijfatigue.2009.06. 022

13. V. Patlan, A. Vinogradov, K. Higashi, K. Kitagawa, Mater Sci Eng A300, 171-182 (2001).

14. A. Washikita, K. Kitagawa, V.I. Kopylov, A. Vinogradov, Ultrafine Grained Materials II, TMS 341350 (2002)

15. J. May, M. Dinkel, D. Amberger, H.W. Höppel, M. Göken, Metal Mater Trans A 38, 1941-1945 (2007) DOI: $10.1007 / \mathrm{s} 11661-007-9110-0$

16. Y. Estrin, A. Vinogradov, Acta Materialia 61(3), 782817 (2013) DOI:org/10.1016/j.actamat.2012.10.038

17. E. Khafizova, R. Islamgaliev, V. Sitdikov, Deformation and fracture of materials 6, 25-29 (2015) (in Russian)

18. E. Khafizova, R. Islamgaliev, G. Klevtsov, E. Merson. Materials Physics and Mechanics 24(3), 232-241 (2015) 